DOI: https://doi.org/10.24867/14CG12Okanovic

\title{
PROCENA STANJA I ENERGETSKA SANACIJA VIŠESPRATNE STAMBENE ZGRADE U ULICI VASE PELAGIĆA U NOVOM SADU
}

\section{ASSESSMENT AND ENERGY RENEWAL OF THE MULTI-STOREY RESIDENTAL BUILDING IN VASE PELAGIĆA STREET IN NOVI SAD}

\author{
Bogdan Okanović, Fakultet tehničkih nauka, Novi Sad
}

\begin{abstract}
Oblast - GRAĐEVINARSTVO
Kratak sadržaj - Rad se sastoji iz dve celine. Prvi deo rada predstavlja teorijsko istraživački deo sa temom „Kontaktne fasade - prednosti i nedostaci" sa fokusom na ETICS sisteme - fasadne termo izolacione sisteme. U drugom delu rada izvršen je vizuelni pregled višespratne stambene zgrade u Novom Sadu, sa ciljem utvrđivanja postojećeg stanja objekta. Za objekat je urađen proračun energetske efikasnosti. Na osnovu ovog proračuna $i$ vizuelnog pregleda zgrade, predložene su sanacione mere koje povećavaju trajnost objekta i njegovu, energetsku efikasnost u skladu sa Pravilnikom o energetskoj efikasnosti.
\end{abstract}

Ključne reči: Procena stanja, energetska efikasnost, sanacione mere, ETICS sistemi

Abstract - The paper consists of two mutually independent units. The first part of the paper presents a theoretical research part with the topic "Contact facades - advantages and disadvantages" with a focus on ETICS systems - facade thermal insulation systems. In the second part of the paper, a visual macroscopic examination of the object was performed, with the aim of determining the existing condition for a multi-storey residential building in Novi Sad. An energy efficiency calculation was performed for the building. Based on this calculation and visual inspection of the structure, remedial measures were given that increase the durability of the building and energy efficiency, regarding the Rulebook on energy efficiency.

Keywords: Assessment, energy efficiency, renewal measures, ETICS systems

\section{UVOD}

Rad se sastoji iz dve celine: teorijsko-istraživačkog dela i stručnog dela. U prvom delu rada analiziraju se kontaktne fasade sa fokusom na ETICS sisteme.

Drugi, stručni deo rada, obuhvata vizuelni pregled konstrukcije i njegovu procenu stanja. Dat je detaljan proračun energetske efikasnosti i priložene su sanacione mere za povećanje trajnosti objekta i energetske efikasnosti.

\section{NAPOMENA:}

Ovaj rad proistekao je iz master rada, čiji je mentor bio prof. dr Vlastimir Radonjanin.

\section{KONTAKTNE FASADE - PREDNOSTI I NEDOSTACI}

Predstavljaju najčešće rešenje prilikom toplotne izolacije objekta i karakteriše ih izolacija direktno pričvršćena na fasadni zid. Još se nazivaju i ETICS fasade

\subsection{OPŠTE O ETICS SISTEMIMA}

ETICS označava spoljni termoizolacioni kompozitni sistem odnosno kompletan skup komponenata, propisno odabranih i proverenih po pitanju kompatibilnosti. ETICS (Slika 1) se odnosi na nanošenje izolacionog materijala $u$ lepku (obično EPS ili mineralna vuna) na spoljnu površinu zida nakon čega sledi sloj armature i mrežica na koji se stavlja osnovni premaz i završni malter.

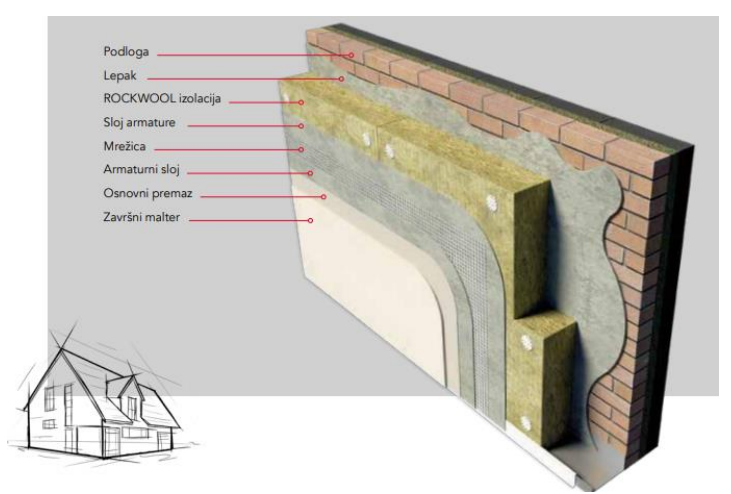

Slika 1. Slojevi ETICS sistema

Trajnost sistema za termoizolaciju zavisi od mnogo faktora. Prvi faktor je praćenje smernica pri nanošenju svake od faza koje su propisane od strane proizvođača. Pored propusta poštovanja osnovnih smernica koje dovode do razaranja sistema, najčešći uzrok prerane degradacije izolacionih sistema je nepropisno izrađivanje detalja, koji se rade na osnovu tehničkog projekta.

Pri montaži obratiti pažnju na:

- Donja ivica termoizolacionih sistema - prvo pričvrstiti početni profil za zid kojim se postavlja nivo za prvi red ploča (visina sokle mora biti definisana). Neravne podloge mogu dovesti do deformacije fiksnih delova, što se izbegava korišćenjem plastične odstojne podloške za bolju nivelaciju i izbegavanje termičkih mostova. Postavljanje ploča kamene vune izvodi se odozdo prema gore sa horizontalnim pomakom od približno pola ploče;

- Dilatacioni spojevi-premošćuju se dilatacionom trakom (poliuretanskom zaptivnom masom); 
- $\quad$ Termoizolacija ivica zgrade - izolacione ploče na uglu zgrade trebalo bi da se preklapaju naizmenično, formirajući ugao;

- Okviri prozora $i$ vrata - posebno su izloženi termičkim mostovima, što dovodi do vlažnih zidova na spojevima drvenarije i do pojave algi i gljivica. Oko ivica može doći do nagomilavanja opterećenja. Termoizolacione ploče isečene $\mathrm{u}$ L-obliku postaviti na takav način da se ne dodiruju na ivicama prozora ili drugim otvorima na fasadi. Ispod i iznad uglova prozora, s ciljem sprečavanja povećanog naprezanja, trebalo bi postaviti trake armaturne mreže pod uglom od $45^{\circ}$;

- Sokla zgrade - je kritičan deo svake fasade, jer je izložena vodi i jakom mehaničkom naprezanju. Za izolaciju sokli preporučuju se posebne vrste EPS sa povećanom otpornošću na vodu i ploče od ekstrudiranog polistirena - XPS, koje moraju biti savršeno složene;

- Balkoni $i$ terase - da bi se osigurao kontinuitet izolacije i smanjili termički mostovi najefikasniji metod je staviti izolaciju sa obe strane celom dužinom ploče odnosno izolacioni se materijal stavlja na dno i na strane.

- Izvođenje pričvrsnica (tipli) - fasadne ploče mehanički se pričvršćuju pričvrsnicama koje moraju da prolaze kroz sloj lepka između ploče i podloge. Prema smernicama proizvođača sistema preporučeno je izvođenje ,W - sheme" pričvrsnica.

\subsection{PREDNOSTI I NEDOSTACI ETICS SISTEMA}

\section{Prednosti:}

- $\quad$ Temperatura prostorije - zimi toplo, leti prijatno I sveže. Odgovarajuća sobna temperatura pretvara dnevnu sobu u prostoriju koja podstiče fizičku dobrobit. Stanovanje postaje udobnije i zdravije.

- Konvekcija - toplotna izolacija obezbeđuje uslove da zidovi održe optimalnu temperaturu, što sprečava neprijatan osećaj usled strujanja vazduha (konvekcije).

- Vlažnost vazduha - dobra termoizolacija smanjuje potrebu za korišćenjem rashladnih uređaja (leti) i grejanja (zimi) i ima očigledno pozitivno dejstvo na vlažnost vazduha.

- Nastanak buđi - odgovarajuća izolacija sprečava nastanak termičkih mostova. To pomaže da se zaustavi pojava kondenzacije, što sprečava nastanak buđi.

- Ušteda energije - dobar fasadni termoizolacioni sistem će vam štedeti do $50 \%$ troškova grejanja - doživotno.

- Ušteda na građevinskim troškovima - pored uštede na troškovima grejanja, primena ETICS sistema može da donese uštedu prilikom građenja, pošto su osmišljeni za primenu na tanjim zidovima. Osim toga, ETICS sistemi praktično ne zahtevaju održavanje.

- Dizajn - ETICS sistemi nude skoro neograničene mogućnosti pri projektovanju u smislu stila, strukture i boje.

\section{Nedostaci:}

- Lako se probija i grebe

- Održavanje - Nanosi peska i prašine lako isprljaju fasadu, čije je čišćenje potom teško i nepraktično. Svaka eventualna popravka oštećenog (udarenog) zida ostavlja fleku.

\section{PROCENA STANJA ZGRADE}

\subsection{TEHNIČKI OPIS}

Stambeni objekat spratnosti $\mathrm{Su}+\mathrm{P}+3+\mathrm{Pk}$ (Slika 2), nalazi se u ulici Vase Pelagića u Novom Sadu. Objekat se pruža u pravcu sever-jug. Oblik objekta je približno pravougaoni, u osnovi dimenzija 29.5m x $18.5 \mathrm{~m}$. Objekat ima jedan ulaz sa strane ulice Vase Pelagića i pasaž za ulaz u garažu i prilaz auto liftu Objekat je po svojoj nameni poslovno-stambeni. U prizemlju su predviđena 4 lokala svaki sa pripadajućim mokrim čvorom. Na spratovima su projektovana po četri stana na etaži $\mathrm{i}$ to na tipskim spratovima I-II-III dva dvosobna, jedan trosoban i jedan četvorosoban.

U potkrovlju je projektovan dvosoban, trosoban, troiposoban i četvoroiposoban stan na dva nivoa (dupleks). Objekat je prema tipu vertikalnih nosećih elemenata skeletna konstrukcija sa platnima za ukrućenje i krutim tavanicama. Obodni zidovi su armiranobetonski do visine suterena, obloženi hidroizolacijom i termoizolacijom. Od visine suterena su zidani blokovima takođe obloženi termoizolacijom.

Međuspratna konstrukcija iznad suterena je AB puna monolitna ploča koja nosi u dva pravca. Ostale međuspratne konstrukcije su polumontažne, sitnorebraste tipa fert (visina gredica $16 \mathrm{~cm}+5 \mathrm{~cm}$ betonska ploča) ukupne debljine $21 \mathrm{~cm}$. Temeljna ploča je puna $A B$ ploča različite debljine od $d=35 \mathrm{~cm}$ do $\mathrm{d}=50 \mathrm{~cm}$. Spratna visina iznosi $291 \mathrm{~cm}$, a čista visina od gotovog poda do tavanice iznosi $260 \mathrm{~cm}$

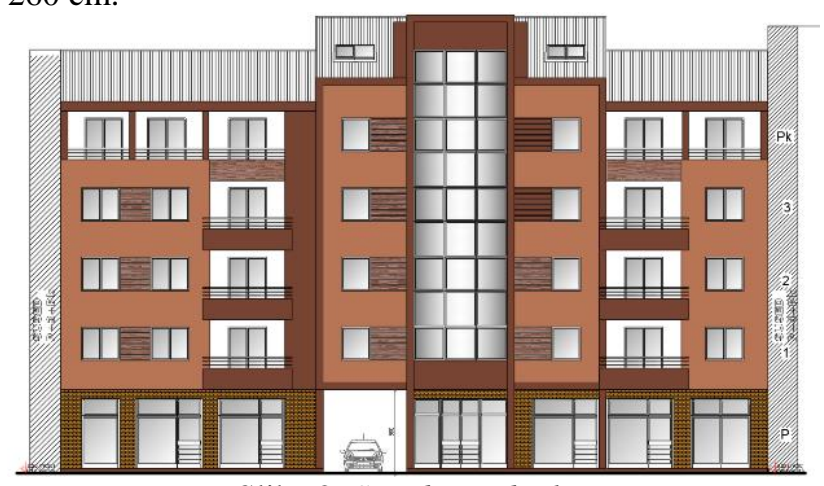

Slika 2. Stambeni objekat

Krov je dvovodni, drveni. Nagib krovnih ravni je različit $i$ iznosi $12^{\circ}, 26^{\circ}$ I $33^{\circ}$, a pokrivanje je izvršeno sa dvostrukim biber crepom. Odvod vode sa krova je predviđen olučnim vertikalama $12 \times 12 \mathrm{~cm}$. Olučne horizontale su u padu prema vertikalama $1.5 \%$.

Spoljašnji zidovi su rađeni $u$ vidu DEMIT fasade. Unutrašnji zidovi su od blokova debljine $\mathrm{d}=25 \mathrm{~cm}$ ili $12 \mathrm{~cm}$ u produženom malteru. Zidne površine su gletovane $\mathrm{i}$ farbane posnom bojom.

\subsection{PROCENA STANJA OBJEKTA}

Prilikom procene stanja konstrukcije obavljen je vizuelni pregled spoljašnjeg i unutrašnjeg dela objekta (suteren $\mathrm{i}$ hodnici svih etaža). Proverene su dimenzije dostupnih elemenata konstrukcije i njihova usklađenost sa projektom predviđenim dimenzijama. Pregledom je utvrđeno da se od glavnog projekta nije odstupalo. Dominantna oštećenja se javljaju u suterenskom delu garaže gde je primetna veća količina vlage u zidovima. (Slika 3) kao i poprilično nemarna obrada zidova suterena - zaostala oplata, vidljiva armatura, odvaljene ivice. 


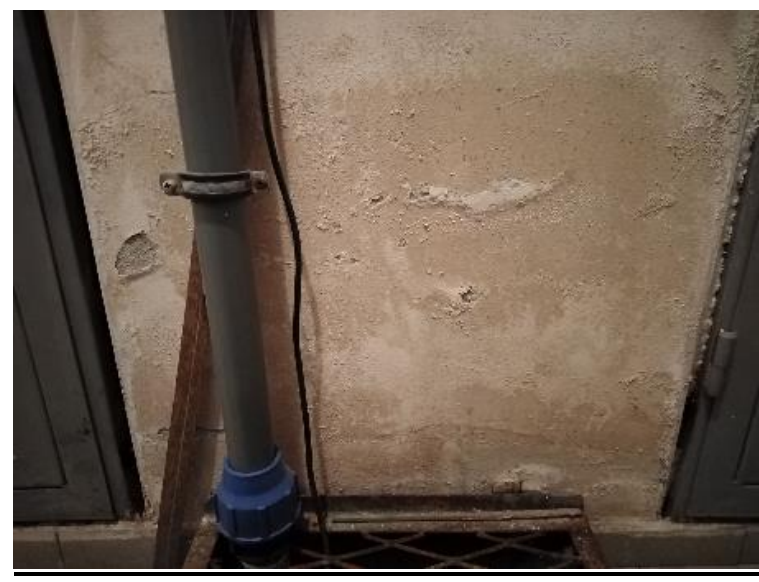

Slika 3. Vlaga u zidovima suterena

Pored oštećenja u suterenu, u dva stana je uočena vlaga $u$ zidovima koja je nastala kao posledica pucanja vodovodnih instalacija. (slika 4). Pored tih, u hodnicima nisu uočena veća oštećenja.

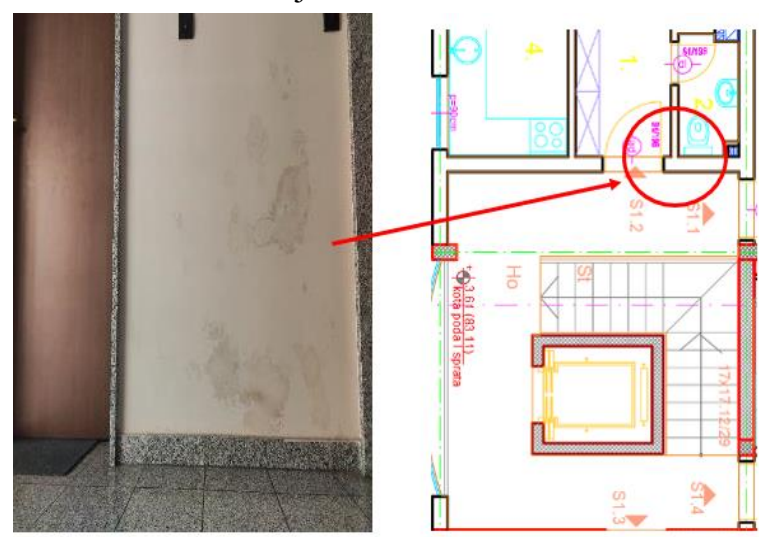

Slika 4. Vlaga u zidovima 1. i 3. sprata

\subsection{ZAKLJUČAK}

Sva registrovana oštećenja ne utiču na nosivost, stabilnost i trajnost konstrukcije. Trajnost objekta je smanjena na pojedinim elementima. Pukotine treba sanirati tehnikom zasecanja i zapunjavanja.

$\mathrm{Na}$ mestima gde je vidljiva armatura potrebno izvršiti reprofilaciju i premazivanje armature antikoro- zionim premazima.

Prsline i sitne pukotine na objektu potrebno je sanirati popunjavanjem sa zaptivnom masom bez prethodnog zasecanja.

\section{ELABORAT ENERGETSKE EFIKASNOSTI}

\subsection{GRAĐEVINSKA FIZIKA}

Pri proračunu energetske efikasnosti urađen je kompletan proračun prolaza toplote kroz građevinske elemente koji čine termički omotač zgrade, proračun difuzije vodene pare, proračun gubitaka i dobitaka toplote, i na kraju proračun godišnje potrebne finalne energije za grejanje.

Ovim proračunom je zaključeno da je postojeći objekat trenutno energetskog razreda $\mathrm{D}$ i da ne zadovoljava energetske zahteve za postojeće objekte prema Pravilniku o energetskoj efikasnosti zgrada.

$\mathrm{U}$ Tabeli 1 dat je pregled koeficijenata prolaza toplote kroz termički omotač objekta.

\begin{tabular}{|c|c|c|c|c|}
\hline ELEMENTI & POZICIJA & $\mathbf{U}\left[\mathbf{W} / \mathbf{m}^{2} \mathbf{K}\right]$ & $\mathbf{U}_{\max }\left[\mathrm{W} / \mathrm{m}^{2} \mathrm{~K}\right]$ & $\begin{array}{c}\text { USLOV } \\
\text { ZADOVOLJEN }\end{array}$ \\
\hline \multirow[t]{2}{*}{ Spoliasnii zidovi } & $\mathrm{Z1}$ & 0.652 & 0.4 & NE \\
\hline & $\mathrm{Z2}$ & 0.545 & 0.4 & $\mathrm{NE}$ \\
\hline \multirow{2}{*}{$\begin{array}{l}\text { Zidovi ka negrejanom } \\
\text { prostoru }\end{array}$} & $\mathrm{Z3}$ & 2.284 & 0.55 & $\mathrm{NE}$ \\
\hline & $\mathrm{Z4}$ & 1.351 & 0.55 & $\mathrm{NE}$ \\
\hline \multirow{3}{*}{ MK iznad negrejanog } & P1 & 0.566 & 0.4 & $\mathrm{NE}$ \\
\hline & \multirow{2}{*}{ P2 } & 0.573 & 0.4 & $\mathrm{NE}$ \\
\hline & & 0.53 & 0.4 & $\mathrm{NE}$ \\
\hline \multirow{2}{*}{$\begin{array}{l}\text { Ravan krov iznad } \\
\text { negrejanog }\end{array}$} & \multirow{2}{*}{ P3 } & 3.5 & 0.2 & $\mathrm{NE}$ \\
\hline & & 2.14 & 0.2 & $\mathrm{NE}$ \\
\hline \multirow[t]{2}{*}{ MK ispod negreinaog } & \multirow{2}{*}{ P4 } & 0.642 & 0.4 & $\mathrm{NE}$ \\
\hline & & 0.575 & 0.4 & $\mathrm{NE}$ \\
\hline \multirow[t]{2}{*}{ Kosi Krov } & \multirow{2}{*}{ P5 } & 0.335 & 0.2 & $\mathrm{NE}$ \\
\hline & & 0.343 & 0.2 & $\mathrm{NE}$ \\
\hline \multirow[t]{10}{*}{ Prozori } & PR1 & 2.948 & 1.5 & $\mathrm{NE}$ \\
\hline & PR2 & 2.953 & 1.5 & $\mathrm{NE}$ \\
\hline & PR3 & 2.91 & 1.5 & $\mathrm{NE}$ \\
\hline & PR4 & 2.89 & 1.5 & $\mathrm{NE}$ \\
\hline & PR5 & 2.91 & 1.5 & $\mathrm{NE}$ \\
\hline & PR6 & 2.93 & 1.5 & $\mathrm{NE}$ \\
\hline & PR7 & 1.75 & 1.5 & $\mathrm{NE}$ \\
\hline & PR8 & 1.76 & 1.5 & NE \\
\hline & PR9 & 1.75 & 1.5 & $\mathrm{NE}$ \\
\hline & PR10 & 1.64 & 1.5 & $\mathrm{NE}$ \\
\hline \multirow[t]{3}{*}{ Vrata } & VR1 & 2.72 & 1.5 & $\mathrm{NE}$ \\
\hline & VR2 & 2.72 & 1.5 & NE \\
\hline & VR3 & 1.9 & 1.5 & $\mathrm{NE}$ \\
\hline
\end{tabular}

Tabela 1. Koeficijent prolaza toplote pre sanacije

$\mathrm{Na}$ Grafiku 1 prikazan je dijagram potrebne energije $\mathrm{u}$ $\mathrm{kWh}$ za grejanje po mesecima. Ukupna godišnja potrebna energija za grejanje je $98026 \mathrm{kWh} / \mathrm{a}$, dok je specifična potrebna godišnja energija $73,95 \mathrm{kWh} / \mathrm{m}^{2} \mathrm{a}$.

Potrebna energija za grejanje po mesecima

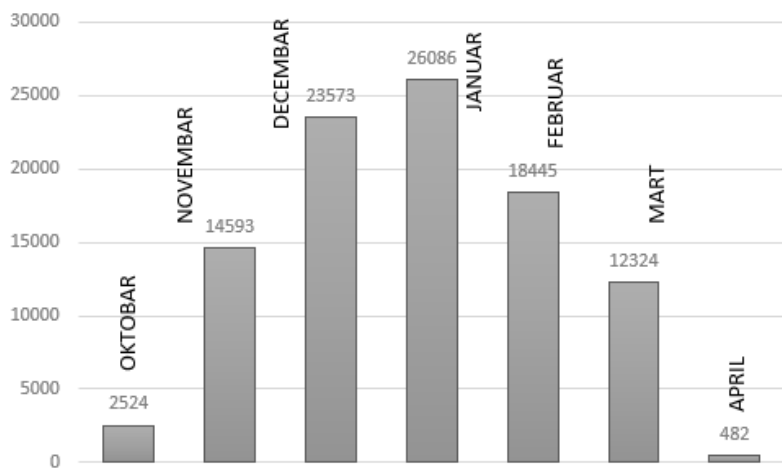

Grafik 1. Dijagram potrebne energije u $k W h$ za grejanje po mesecima

\section{MERE ZA UNAPREĐENJE ENERGETSKE EFIKASNOSTI}

U cilju poboljšanja energetskih potreba i svojstava zgrade predviđena je sledeća sanacija pojedinih zidova, delova međuspratnih konstrukcija i fasadnih prozora. Spoljašnji zidovi su već sistema sličnog ETICS sistemu te oni neće biti unapređivani. Unutrašnji hodnički zidovi su unapredđeni dodavanjem ogovarajuće debljine ETICS sistema. Međuspratna konstrukcija suterena, međuspratna konstrukcija iznad skloništa i garaže ne zadovoljavaju zahteve $\mathrm{u}$ pogledu maksimalnog koeficijenta prolaza toplote. Predlaže se poboljšanje u vidu postavljanja stiropora sa donje strane. Međuspratna konstrukcija ka negrejanom tavanskom prostoru biće takođe, poboljšana stiroporom sa gornje strane. Debljina sloja kamene vune, odsnosno ekspandiranog polistirena, određena je iz uslova zadovoljenja maksimalnog dozvoljenog koeficijenta prolaza toplote. Za potrebe proračuna ETICS sisetam korišćene su tehničke karakteristike proizvođača "ROCKWOOL". Za sve otsale tehhničke karakteristike su uzete iz Pravilnika o energetskoj efikasnosti zgrada ("Sl.glasnik RS", br. 61/2011, Beograd). Pored zidova 
vršena je zamena fasadnih prozora ge je menjano staklo (prozirno u niskoemisiono): $\mathrm{U}$ Tabeli 2 dat je pregled koeficijenata prolaza toplote kroz termički omotač objekta posle energetske sanacije.

\begin{tabular}{|c|c|c|c|c|}
\hline ELEMENTI & POZICIJA & $\mathrm{U}\left[\mathrm{W} / \mathrm{m}^{\mathbf{2}} \mathrm{K}\right]$ & $\mathbf{U}_{\max }\left[\mathrm{W} / \mathrm{m}^{2} \mathrm{~K}\right]$ & $\begin{array}{c}\text { USLOV } \\
\text { ZADOVOLJEN }\end{array}$ \\
\hline \multirow[t]{2}{*}{ Spoljasnii zidovi } & $\mathrm{Z1}$ & 0.652 & 0.4 & $\mathrm{NE}$ \\
\hline & $\mathrm{Z2}$ & 0.545 & 0.4 & $\mathrm{NE}$ \\
\hline \multirow{2}{*}{$\begin{array}{l}\text { Zidovi ka negrejanom } \\
\text { prostoru }\end{array}$} & 23 & 0.377 & 0.55 & DA \\
\hline & $\mathrm{Z4}$ & 0.338 & 0.55 & DA \\
\hline \multirow[t]{2}{*}{ MK iznad negrejanog } & P1 & 0.334 & 0.4 & DA \\
\hline & P2 & 0.3104 & 0.4 & DA \\
\hline Ravan krov iznad negrejanog & P3 & 3.5 & 0.2 & $\mathrm{NE}$ \\
\hline MK ispod negrejnaog & P4 & 0.345 & 0.4 & DA \\
\hline Kosi Krov & P5 & 0.341 & 0.2 & $\mathrm{NE}$ \\
\hline \multirow[t]{10}{*}{ Prozori } & PR1 & 1.87 & 1.5 & $\mathrm{NE}$ \\
\hline & PR2 & 1.84 & 1.5 & $\mathrm{NE}$ \\
\hline & PR3 & 2.08 & 1.5 & $\mathrm{NE}$ \\
\hline & PR4 & 1.91 & 1.5 & $\mathrm{NE}$ \\
\hline & PR5 & 1.86 & 1.5 & $\mathrm{NE}$ \\
\hline & PR6 & 1.94 & 1.5 & $\mathrm{NE}$ \\
\hline & PR7 & 1.75 & 1.5 & NE \\
\hline & PR8 & 1.76 & 1.5 & $\mathrm{NE}$ \\
\hline & PR9 & 1.75 & 1.5 & $\mathrm{NE}$ \\
\hline & PR10 & 1.64 & 1.5 & $\mathrm{NE}$ \\
\hline \multirow[t]{3}{*}{ Vrata } & VR1 & 2.72 & 1.5 & $\mathrm{NE}$ \\
\hline & VR2 & 2.72 & 1.5 & NE \\
\hline & VR3 & 1.9 & 1.5 & NE \\
\hline
\end{tabular}

Tabela 2. Koeficijent prolaza toplote nakon sanacije

$\mathrm{Na}$ Grafiku 2 prikazan je dijagram potrebne energije u kWh za grejanje po mesecima. Ukupna godišnja potrebna energija za grejanje je $78853 \mathrm{kWh} / \mathrm{a}$, dok je specifična potrebna godišnja energija $59,49 \mathrm{kWh} / \mathrm{m}^{2} \mathrm{a}$.

Potrebna energija za grejanje po mesecima

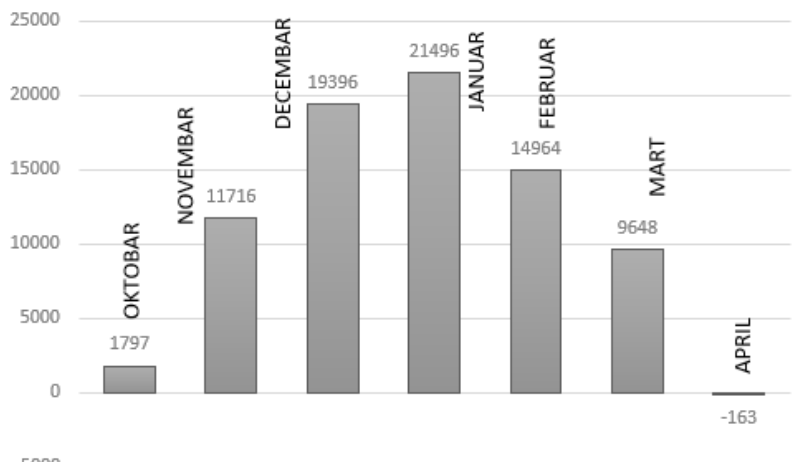

Grafik 2. Dijagram potrebne energije u $k W h$ za grejanje po mesecima nakon izvršene sanacije

Nakon uvođenja predloženih mera za termičku sanaciju i ponovnog proračuna energetske efikasnosti, potreba za energijom na godišnjem nivou sa značajno smanjila. Energetski razred se popravio i sada objekat pripada $\mathrm{C}$ razredu.

Objekat sada zadovoljava uslove po pitanju energetske efikasnosti u skladu sa Pravilnikom o energetskoj efikasnosti (Sl. glasnik RS br.061/2011).

\section{LITERATURA}

[1] Inženjerska komora Srbije: Pravilnik o energetskoj efikasnosti zgrada, "Sl.glasnik RS", br. 61/2011, Beograd

[2] Inženjerska komora Srbije: Pravilnik o tehničkim zahtevima bezbednosti od požara spoljnih zidova zgrada, "Sl.glasnik RS", br. 59/2016, 36/2017 i 6/2019 Beograd

[3] Malešev M., Radonjanin V.: Trajnost i procena stanja betonskih konstrukcija, Skripta sa predavanja, Fakultet tehničkih nauka, Novi Sad

[4] Radonjanin V., Malešev M.: Sanacija betonskih konstrukcija, Skripta sa predavanja, Fakultet tehničkih nauka, Novi Sad

[5] Rešenja i proizvodi ROCKWOOL: www.rockwool.rs

[6] Glavni arhitektonski projekat broj E-20/08 izrađen od strane URBIS DOO, u Novom Sadu.

\section{Kratka biografija:}

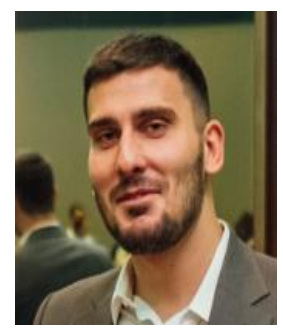

Bogdan Okanović rođen je u Novom Sadu, 1994. godine. Osnovne akademske studije završio je na Fakultetu tehničkih nauka 2018. godine, iz oblasti građevinarstvo konstruktivni smer. Diplomski rad radilo je iz predmeta Organizacija građenja. Master akadamske studije smer - konstrukcije upisao je iste godine. Master rad iz oblasti Procena stanja i sanacija konstrukcija, uradio je i odbranio u 2021. godini. 